\title{
Pajanan Kebisingan dan Hipertensi di Kalangan Pekerja Pelabuhan
}

\author{
Noise Exposure and Hypertension among Harbor Worker
}

\author{
Eddy Harianto* Hadi Pratomo**
}

\begin{abstract}
*Kantor Kesehatan Pelabuhan Tarakan Kalimantan Utara, **Departemen Pendidikan Kesehatan dan Ilmu Perilaku Fakultas Kesehatan Masyarakat Universitas Indonesia
\end{abstract}

\begin{abstract}
Abstrak
Penyakit kardiovaskular menempati urutan ke-4 atau 15\% dari penyebab kematian yang berhubungan dengan pekerjaan. Hipertensi yang merupakan salah satu penyakit pembuluh darah, dikenal sebagai silent killer karena sering tidak menimbulkan gejala. Sebagian besar penderita hipertensi di Indonesia tidak terdeteksi, sementara mereka yang terdeteksi umumnya tidak menyadari kondisi penyakitnya dan hanya sebagian kecil yang berobat secara teratur. Tujuan penelitian ini untuk mengetahui prevalensi hipertensi pada pekerja pelabuhan di wilayah kerja Kantor Kesehatan Pelabuhan Kelas II Tarakan serta faktor-faktor risiko yang berpengaruh. Desain penelitian yang digunakan adalah potong lintang; subjek diperoleh dari hasil survei penyakit tidak menular tahun 2011 oleh Kantor Kesehatan Pelabuhan Tarakan. Subjek yang terkumpul adalah 361 pekerja. Nilai pengukuran tekanan darah menggunakan nilai baku dari JNC VII tahun 2003. Prevalensi hipertensi ditemukan lebih rendah daripada angka nasional dan provinsi, yaitu 21,88\%. Pajanan kebisingan dikaitkan dengan usia, riwayat keluarga hipertensi, stres, indeks massa tubuh dan berhubungan dengan hipertensi.
\end{abstract}

Kata kunci: Hipertensi, pajanan kebisingan, pekerja pelabuhan

\footnotetext{
Abstract

Cardiovascular disease range ranks fourth or $15 \%$ of the causes of death related to job. Hipertension is one of cardiovascular disease thet is known as silent killer because of lack of simptom. Most of hypertension patients in Indonesia are not detected, while they are whose detected do not conscious their disease condition and only little who get the treatment regularly. The objective of this study was to know the prevalence and risk factors of hypertension among harbor worker at Port Health Office Class II of Tarakan with it's associated risk factors. The study design used was crosssectional. The study used secondary data source of noncommunicable disease survey, 2011 at Port Health Office of Tarakan. The subjects were 361 workers. Value of blood pressure measurement using the raw value of the
}

JNC VII IN 2003. The prevalence of hypertension were found lower than national and province indicator score, $21,88 \%$. Noise exposure is associated with hypertension together with age, family hypertension history, stress, body mass index.

Keywords: Hypertension, noise exposure, harbor worker

\section{Pendahuluan}

Transisi epidemiologi penyakit adalah kecenderungan perubahan pola kesakitan berupa penurunan prevalensi penyakit infeksi dan peningkatan prevalensi penyakit noninfeksi atau penyakit degeneratif seperti hipertensi, stroke, kanker, diabetes mellitus. ${ }^{1}$ Transisi epidemiologi yang paralel dengan transisi demografi dan transisi teknologi di Indonesia dewasa ini mengakibatkan perubahan pola penyakit dari penyakit infeksi ke penyakit tidak menular (PTM) meliputi penyakit degeneratif dan man made diseases. Transisi epidemiologi tersebut disebabkan oleh perubahan sosial ekonomi, lingkungan dan perubahan struktur penduduk, ketika masyarakat mengadopsi gaya hidup tidak sehat, seperti merokok, kurang aktivitas fisik, makanan tinggi lemak dan kalori, serta konsumsi alkohol yang diduga merupakan faktor risiko PTM. Pada abad ke-21, diperkirakan terjadi peningkatan insidens dan prevalensi PTM secara cepat, yang merupakan tantangan utama masalah kesehatan pada masa yang akan datang. World Health Organization (WHO) memperkirakan, pada tahun 2020, PTM menjadi penyebab $73 \%$ kematian dan $60 \%$ seluruh kesakitan

Alamat Korespondensi: Eddy Harianto, Kantor Kesehatan Pelabuhan Tarakan, Jl. Mulawarman 1 Tarakan Kalimantan Utara, Hp. 081319218968 , e-mail: eddie_mae@ymail.com 
di dunia. Diperkirakan negara yang paling merasakan dampak tersebut adalah negara berkembang termasuk Indonesia. ${ }^{2}$

Hipertensi yang merupakan salah satu penyakit pembuluh darah, dikenal sebagai silent killer, karena sering tidak menimbulkan gejala. Sebagian besar penderita hipertensi di Indonesia tidak terdeteksi, sementara mereka yang terdeteksi umumnya tidak menyadari kondisi penyakitnya dan hanya sebagian kecil yang berobat secara teratur. ${ }^{3}$ Pada tahun 2000, diperkirakan 972 juta $(26 \%)$ orang dewasa di dunia menderita hipertensi. Angka ini terus meningkat, diprediksikan oleh WHO pada tahun 2025 sekitar 29\% orang dewasa diseluruh dunia yang menderita hipertensi. ${ }^{4}$ Penyakit kardiovaskular menempati urutan ke-4 atau $15 \%$ dari penyebab kematian yang berhubungan dengan pekerjaan. ${ }^{5}$ Prevalensi hipertensi pada pekerja usia 35 sampai 55 tahun di Indonesia tahun 2005 menurut penelitian Rundengan, ${ }^{6}$ yaitu sebesar $15,1 \%$. Dari hasil penelitian Nirmawati, ${ }^{7}$ didapatkan prevalensi hipertensi anak buah kapal yang terpajan bising di Dit Pol Air Babinkam Polri tahun 2010 sebesar $31,1 \%$. Pada orang yang berumur di atas 40 tahun di 11 provinsi di Indonesia, ditemukan bahwa proporsi wanita yang menderita hipertensi $25,4 \%$ dan pria yang menderita hipertensi $40,3 \% .8$

Survei oleh Monica di Jakarta menemukan bahwa subjek dengan beban kerja berat, yang berisiko hipertensi lebih rendah. Mereka adalah para pekerja yang meningkatkan denyut jantung dan pernapasan dan berkeringat atau sebanding dengan beban lebih dari 7 MET/8 $\mathrm{kkal} / 25 \mathrm{ml} / \mathrm{kg} / \mathrm{menit}$, seperti pada buruh dan pekerja kasar atau petani. Demikian pula dengan kebiasaan berolahraga, yang teratur dua kali seminggu, sekurangnya 20 menit tiap kalinya, dan yang berolahraga tidak teratur, dengan jenis olahraga; senam, berjalan, joging, lari, bulu tangkis, sepak bola, bola voli, golf atau lontar martil. ${ }^{9}$

Sekitar 99\% penderita hipertensi dengan penyebab tidak diketahui dikenal sebagai hipertensi esensial atau hipertensi primer. Hipertensi esensial adalah penyakit multifaktorial yang timbul karena interaksi antara faktorfaktor risiko tertentu. Modifikasi gaya hidup adalah upaya terbaik dalam mencegah dan menangani tekanan darah tinggi selain terapi dengan obat. ${ }^{10}$ Hubungan tingkat kegemukan dengan hipertensi bersifat protektif prevalence odds ratio $(\mathrm{POR})=0,55(95 \% \mathrm{CI}=0,36-$ 0,85). ${ }^{11}$ Berbagai studi tentang faktor risiko hipertensi memperlihatkan hasil yang bervariasi ada yang tidak signifikan dan ada yang signifikan. Prevalensi dan insiden hipertensi pada tiap negara menampilkan angka nasional yang sangat beragam dan mempunyai variasi geografi. ${ }^{12}$

Kantor Kesehatan Pelabuhan Kelas II Tarakan secara geografis berada di bagian utara Kalimantan Timur, dengan wilayah kerja yang tersebar pada beberapa kabupaten/kota meliputi, Pelabuhan Laut Tarakan, Pelabuhan
Udara Juwata Tarakan, Pelabuhan Laut Nunukan, Pelabuhan Laut Bunyu, Pelabuhan Laut Sei Nyamuk dan Pelabuhan Laut Berau. Penelitian ini bertujuan untuk mengetahui frekuensi, distribusi hipertensi dan faktorfaktor risiko hipertensi pada pekerja pelabuhan di wilayah kerja Kantor Kesehatan Pelabuhan Kelas II Tarakan.

\section{Metode}

Desain studi yang digunakan adalah desain studi potong lintang. dengan mengkaji prevalensi hipertensi dan faktor-faktor risiko yang berpengaruh. Populasi target adalah seluruh pekerja pelabuhan di wilayah kerja Kantor Kesehatan Pelabuhan Kelas II Tarakan pada tahun 2011, sedangkan subjek adalah bagian dari populasi penelitian menurut laporan Survei PTM Kantor Kesehatan Pelabuhan Kelas II Tarakan tahun 2011. Sebanyak 361 pekerja dijadikan subjek penelitian. Cara pengambilan sampel dilakukan dengan simple random sampling

Hipertensi ditentukan berdasarkan kriteria 7 th joint national committee (JNC 7) yang mengklasifikasikan hipertensi dikelompokkan menjadi normal (sistolik < 120 $\mathrm{mmHg}$ dan diastolik $<80 \mathrm{mmHg}$ ), pre hipertensi (sistolik 120 - $139 \mathrm{mmHg}$ atau diastolik $80-89 \mathrm{mmHg}$ ), hipertensi tahap I (sistolik 140 - $159 \mathrm{mmHg}$ atau diastolik $90-99 \mathrm{mmHg}$ ), dan hipertensi tahap II (sistolik $\geq$ $160 \mathrm{mmHg}$ atau diastolik $\geq 100 \mathrm{mmHg}$ ). Penentuan hipertensi dikelompokkan menjadi normal $(<140 / 90$ $\mathrm{mmHg}$ ) dan hipertensi ( $\geq 140$ dan atau $\geq 90 \mathrm{mmHg}$ ). Variabel independen meliputi usia, jenis kelamin, riwayat keluarga hipertensi, merokok, konsumsi alkohol, olahraga, stres, indeks massa tubuh (IMT), masa kerja, area kerja, unit kerja, dan pajanan kebisingan. Data diolah dan dianalisis dengan program statistik. Analisis bivariat digunakan untuk memilih variabel kandidat untuk masuk ke analisis multivariat. Variabel yang akan diuji multivariat adalah yang mempunyai nilai $p \leq 0,25$ dari hasil uji bivariat. Untuk melihat hubungan variabel independen dan variabel dependen dengan menggunakan uji statistik kai kuadrat dengan tingkat kemaknaan adalah $\alpha=0,05$, dan juga dinilai POR dan presisi (rentang interval kepercayaan 95\%). Analisis multivariat selanjutnya digunakan untuk melihat kekuatan hubungan antara variabel independen dan variabel dependen dan menentukan faktor mana yang paling kuat hubungannya dengan variabel dependen. Uji statistik yang digunakan adalah uji statistik regresi logistik. Setelah itu, variabel dimasukkan satu per satu ke dalam model regresi logistik dengan metode enter dengan mempertimbangkan substansi dan nilai $\mathrm{p}$ untuk mendapatkan full model.

\section{Hasil}

Jumlah subjek pada penelitian ini adalah 361 pekerja. Berdasarkan karakteristik individu sebagian besar berumur $28-42$ tahun $(46,26 \%)$ dan didominasi oleh la- 
ki-laki $(77,56 \%)$. Sebagian besar tidak mempunyai riwayat keluarga hipertensi $(86,70 \%)$, tidak mempunyai kebiasaan merokok $(56,51 \%)$, tidak mengonsumsi alkohol $(88,92 \%)$, lebih banyak yang tidak rutin berolahraga $(58,17 \%)$, tidak mengalami stres $(78,95 \%)$. Dari pengukuran IMT, sebagian besar pekerja mempunyai proporsi IMT normal $(60,66 \%)$ dan diikuti oleh obesitas $(18,56 \%)$. Berdasarkan karakteristik pekerjaan sebagian besar pekerja mempunyai masa kerja kurang dari enam tahun $(51,52 \%)$, proporsi unit kerja operasional lebih tinggi $(81,16 \%)$, area kerja lebih besar pada pelabuhan udara $(54,02 \%)$ namun hampir sama dengan pelabuhan laut $(45,98 \%)$.Lebih banyak pekerja yang terpajan kebisingan $(55,96 \%)$ (Tabel 1).

Prevalensi kejadian hipertensi pada pekerja pelabuhan di wilayah kerja Kantor Kesehatan Pelabuhan Kelas II Tarakan tahun 2011 adalah 21,88\% dari 361 pekerja (Tabel 2). Berdasarkan hubungan karakteristik individu dan pekerjaan dengan hipertensi, variabel yang dapat dianalisis secara multivariat adalah variabel yang memiliki nilai $\mathrm{p}<0,05$, yaitu usia $27-28$ tahun dan $>42$ tahun, jenis kela-min, riwayat keluarga hipertensi,

Tabel 1. Karakteristik Individu Responden

\begin{tabular}{|c|c|c|c|}
\hline Karakteristik & Kategori & $\mathbf{n}$ & $\%$ \\
\hline \multirow[t]{3}{*}{ Usia (tahun) } & $18-27$ & 110 & 30,47 \\
\hline & $28-42$ & 167 & 46,26 \\
\hline & $>42$ & 84 & 23,27 \\
\hline \multirow[t]{2}{*}{ Jenis kelamin } & Perempuan & 81 & 22,44 \\
\hline & Laki-laki & 280 & 77,56 \\
\hline \multirow[t]{2}{*}{ Riwayat keluarga hipertensi } & Ada & 48 & 13,30 \\
\hline & Tidak & 313 & 86,70 \\
\hline \multirow[t]{2}{*}{ Merokok } & Ya & 157 & 43,49 \\
\hline & Tidak & 204 & 56,51 \\
\hline \multirow[t]{2}{*}{ Konsumsi alkohol } & Ya & 40 & 11,08 \\
\hline & Tidak & 321 & 88,92 \\
\hline \multirow[t]{2}{*}{ Olahraga } & Rutin & 151 & 41,83 \\
\hline & Tidak rutin & 210 & 58,17 \\
\hline \multirow[t]{2}{*}{ Stres } & Ya & 76 & 21,05 \\
\hline & Tidak & 285 & 78,95 \\
\hline \multirow[t]{4}{*}{ Indeks massa tubuh } & Kurus & 18 & 4,99 \\
\hline & Normal & 219 & 60,66 \\
\hline & Gemuk & 57 & 15,79 \\
\hline & Obesitas & 67 & 18,56 \\
\hline \multirow[t]{3}{*}{ Masa kerja } & $<6$ & 186 & 51,52 \\
\hline & $6-12$ & 86 & 23,82 \\
\hline & $>12$ & 89 & 24,65 \\
\hline \multirow[t]{2}{*}{ Unit kerja } & Administrasi & 68 & 18,84 \\
\hline & Operasional & 293 & 81,16 \\
\hline \multirow[t]{2}{*}{ Area kerja } & Pelabuhan laut & 166 & 45,98 \\
\hline & Pelabuhan udara & 195 & 54,02 \\
\hline \multirow[t]{2}{*}{ Terpajan kebisingan } & Ya & 202 & 55,96 \\
\hline & Tidak & 159 & 44,04 \\
\hline
\end{tabular}

Tabel 2. Prevalensi Hipertensi pada Pekerja Pelabuhan

\begin{tabular}{llll}
\hline Variabel & Kategori & $\mathbf{n}$ & $\%$ \\
\hline Hipertensi & Hipertensi & 79 & 21,88 \\
& Tidak hipertensi & 282 & 78.12 \\
\hline
\end{tabular}

merokok, stres, indeks massa tubuh gemuk dan obesitas, masa kerja $6-12$ tahun dan > 12 tahun, area kerja, dan terpajan kebisingan (Tabel 3).

Analisis multivariat yang dilakukan pada beberapa variabel yang memiliki hubungan karakteristik individu dan pekerjaan dengan hipertensi. Dari hasil analisis, variabel yang berpengaruh secara signifikan terhadap hipertensi adalah usia, riwayat keluarga hipertensi, dan terpajan kebisingan (nilai $\mathrm{p}<0,05)$ (Tabel 4).

Hasil akhir analisis menunjukkan bahwa variabel yang paling berpengaruh terhadap hipertensi adalah indeks massa tubuh obesitas, yang memiliki nilai POR = 6,97 . Faktor-faktor lain yang juga berpengaruh adalah usia $>42$ tahun, riwayat keluarga hipertensi, dan terpajan kebisingan (Tabel 5).

\section{Pembahasan}

Hasil laporan Riskesdas 2007, prevalensi nasional hipertensi pada penduduk usia $>18$ tahun adalah sebesar 31,7\%.13 Di Provinsi Kalimantan Timur, prevalensi hipertensi dilaporkan sekitar 31,3\%, di Kota Tarakan, prevalensi hipertensi termasuk tinggi sekitar 36\% melebihi angka prevalensi Provinsi Kalimantan Timur dan angka prevalensi nasional. Sedangkan prevalensi hipertensi di Provinsi Jawa sekitar 41,9\%. ${ }^{14}$

Prevalensi hipertensi pada pekerja pelabuhan di wilayah kerja Kantor Kesehatan Pelabuhan Kelas II Tarakan tahun 2011 adalah 21,88\%, meskipun angka ini tergolong rendah di bawah angka prevalensi Kalimantan Timur dan angka prevalensi Kota Tarakan. Namun, potensi kejadian hipertensi akan jauh lebih besar lagi karena banyak faktor yang memengaruhinya, terlebih lagi angka tersebut berada diatas kisaran hipertensi yang terjadi pada populasi umum yaitu $15-20 \%$. Sedangkan pada penelitian Rundengan, ${ }^{6}$ prevalensi hipertensi pada pekerja di Indonesia tahun 2005 adalah sebesar 15,1\%.

Pada penelitian ini, secara konsisten didapatkan prevalensi hipertensi pada pekerja meningkat sejalan dengan pertambahan usia, pada kelompok usia 18 - 27 tahun sekitar $12,73 \%$, pada usia $28-42$ tahun naik menjadi $17,96 \%$ dan semakin tinggi pada usia $>42$ tahun yaitu $41,67 \%$. Usia $>42$ tahun menunjukkan hubungan bermakna dengan kejadian hipertensi, hasil uji statistik didapatkan nilai $\mathrm{p}=0,000$ dengan $\mathrm{POR}=5,89(95 \% \mathrm{CI}=$ $1,89-18,33)$. Hasil ini sesuai dengan penelitian sebelumnya yang mendapatkan bahwa dengan semakin meningkatnya usia, risiko mendapat hipertensi juga meningkat. Meningkatnya risiko sesuai dengan pertambahan usia disebabkan oleh perubahan alami pada jantung, pembuluh darah, dan hormon. ${ }^{15}$ Prevalensi pekerja usia 35 - 40 tahun $23,2 \%$ sedangkan usia 41 - 55 tahun $76,8 \%$. Penelitian Rundengan, ${ }^{6}$ juga mendapatkan hubungan usia dengan hipertensi bermakna (nilai $\mathrm{p}=$ 0,000) dengan $\mathrm{OR}=2,95(95 \% \mathrm{CI}=2,29-3,79)$ 
Tabel 3. Hubungan Karakteristik Individu dan Pekerjaan dengan Hipertensi

\begin{tabular}{|c|c|c|c|c|}
\hline Variabel & Kategori & POR & $95 \%$ CI & Nilai $p$ \\
\hline \multirow[t]{3}{*}{ Usia (tahun) } & $18-27$ & & & \\
\hline & $28-42$ & 1,5 & $0,76-2,98$ & $0,245^{*}$ \\
\hline & $>42$ & 4,89 & $2,41-9,95$ & $0,000^{*}$ \\
\hline \multirow[t]{2}{*}{ Jenis kelamin } & Perempuan & & & \\
\hline & Laki-laki & 2,67 & $1,27-5,61$ & $0,010^{*}$ \\
\hline \multirow[t]{2}{*}{ Riwayat keluarga hipertensi } & Ada & 0,57 & $0,29-1,10$ & $0,095^{*}$ \\
\hline & Tidak & & & \\
\hline \multirow[t]{2}{*}{ Merokok } & Ya & 0,74 & $0,45-1,21$ & $0,234 *$ \\
\hline & Tidak & & & \\
\hline \multirow{2}{*}{ Konsumsi alkohol } & Ya & 0,71 & $0,34-1,49$ & 0,364 \\
\hline & Tidak & & & \\
\hline \multirow[t]{2}{*}{ Olahraga } & Rutin & & & \\
\hline & Tidak rutin & 0,88 & $0,53-1,45$ & 0,614 \\
\hline \multirow{2}{*}{ Stres } & Ya & 1,64 & $0,83-3,22$ & $0,151^{*}$ \\
\hline & Tidak & & & \\
\hline \multirow[t]{4}{*}{ Indeks massa tubuh } & Kurus & & & \\
\hline & Normal & & & \\
\hline & Gemuk & 1,84 & $0,98-3,44$ & $0,056^{*}$ \\
\hline & Obesitas & 2,88 & $1,62-5,12$ & $0,000^{*}$ \\
\hline \multirow[t]{3}{*}{ Masa kerja (tahun) } & $<6$ & & & \\
\hline & $6-12$ & 1,02 & $0,52-1,99$ & 0,962 \\
\hline & $>12$ & 2,7 & $1,52-4,81$ & $0,001 *$ \\
\hline \multirow[t]{2}{*}{ Unit kerja } & Administrasi & 0,89 & $0,48-1,66$ & 0,716 \\
\hline & Operasional & & & \\
\hline \multirow[t]{2}{*}{ Area kerja } & Pelabuhan laut & 0,65 & $0,39-1,07$ & $0,09^{*}$ \\
\hline & Pelabuhan udara & & & \\
\hline \multirow[t]{2}{*}{ Terpajan kebisingan } & Ya & 0,63 & $0,38-1,06$ & $0,083^{*}$ \\
\hline & Tidak & & & \\
\hline
\end{tabular}

Keterangan: *masuk kandidat model melalui analisis multivariat (nilai $\mathrm{p}<0,25$ )

Tabel 4. Analisis Multivariat Faktor-faktor yang Berpengaruh terhadap Hipertensi

\begin{tabular}{lllll}
\hline Variabel & B & POR & 95\% CI & Nilai $\mathbf{p}$ \\
\hline Usia (tahun) & & & & \\
$28-27$ & 0,51 & 1,66 & $0,73-3,79$ & 0,22 \\
$\quad>42$ & 1,77 & 5,89 & $1,89-18,33$ & $0,00^{*}$ \\
Jenis kelamin & 0,58 & 1,78 & $0,71-4,46$ & 0,22 \\
Riwayat keluarga hipertensi & $-0,89$ & 0,41 & $0,19-0,89$ & $0,03^{*}$ \\
Merokok & $-0,35$ & 0,71 & $0,38-1,31$ & 0,27 \\
Stres & 0,76 & 2,13 & $0,97-4,67$ & 0,06 \\
$\quad$ Indeks massa tubuh & & & & \\
$\quad$ Gemuk & 1,23 & 3,53 & $0,39-31,29$ & 0,26 \\
$\quad$ Obesitas & 1,74 & 5,66 & $0,67-47,54$ & 0,11 \\
$\quad$ Masa kerja (tahun) & & & & \\
$\quad$ 6-12 & $-0,78$ & 0,46 & $0,19-1,06$ & 0,07 \\
$\quad>12$ & $-0,42$ & 0,66 & $0,25-1,74$ & 0,39 \\
Area kerja & $-0,31$ & 0,73 & $0,41-1,30$ & 0,29 \\
Terpajan kebisingan & $-0,65$ & 0,52 & $0,29-0,95$ & $0,03^{*}$ \\
\hline
\end{tabular}

Keterangan: *signifikan (nilai $\mathrm{p}<0,05$ )

Pada penelitian ini, prevalensi hipertensi pada pekerja laki-laki $(25 \%)$ lebih tinggi dari pekerja perempuan $(11,11 \%)$. Jenis kelamin tidak menunjukkan hubungan bermakna dengan kejadian hipertensi, hasil uji statistik didapatkan nilai $\mathrm{p}=0,22$ dengan POR $1,78(95 \% \mathrm{CI}=$ $0,71-4,46)$. Pada usia dini tidak terdapat bukti nyata perbedaan tekanan darah laki-laki dan perempuan, setelah remaja laki-laki cenderung lebih tinggi dari perem-
Tabel 5. Model Akhir Faktor-faktor yang Berpengaruh terhadap Hipertensi

\begin{tabular}{lllll}
\hline Variabel & B & POR & $\mathbf{9 5 \%}$ CI & Nilai p \\
\hline Umur (tahun) & & & & \\
$\quad 28-42$ & 0,61 & 1,46 & $0,63-3,69$ & 0,46 \\
$\quad \begin{array}{l}>42 \\
\text { Riwayat keluarga hipertensi }\end{array}$ & 1,43 & 4,19 & $1,92-8,58$ & 0,00 \\
Stres & $-0,89$ & 0,41 & $0,19-0,89$ & 0,03 \\
Indeks massa tubuh & 0,78 & 2,15 & $0,99-4,67$ & 0,08 \\
$\quad$ Gemuk & & & & \\
$\quad$ Obesitas & 1,73 & 4,84 & $0,28-45,14$ & 0,14 \\
$\quad$ Terpajan kebisingan & 1.94 & 6.97 & $0,89-61,39$ & 0,07 \\
& $-0,69$ & 0,56 & $0,33-0,99$ & 0,04 \\
\hline
\end{tabular}

puan, perbedaan ini akan lebih jelas pada orang dewasa muda dan orang setengah baya. Pada pekerja laki-laki, tekanan pekerjaan memungkinkan mereka menderita hipertensi lebih tinggi dari perempuan. ${ }^{6,11}$

Prevalensi hipertensi pada pekerja yang mempunyai riwayat keluarga dengan hipertensi adalah 31,25\% sedangkan di antara pekerja yang tidak mempunyai riwayat keluarga hipertensi adalah $20,64 \%$. Secara statistik, ada hubungan bermakna antara riwayat keluarga dengan hipertensi (nilai $p=0,03$ ). Namun, hubungan yang ada bersifat protektif dengan POR 0,41 (95\% CI = 0,19 $-0,89)$. Namun, hal ini perlu dicermati agar tidak dianggap bahwa pekerja dengan riwayat keluarga hipertensi seolah-olah lebih baik. Fuentes, ${ }^{16}$ mengemukakan bahwa terdapat korelasi yang bermakna antara tekanan darah 
ibu dengan tekanan darah sistolik keturunan, dan terdapat korelasi bermakna antara mean arterial pressure $=$ tekanan nadi (MAP) ayah dengan MAP keturunan. Keadaan tersebut dapat terjadi akibat bias informasi. Mereka yang sebenarnya mempunyai anggota keluarga hipertensi, tetapi tid ak mengetahuinya ikut terklasifikasi ke dalam kelompok yang tidak mempunyai riwayat keluarga hipertensi.

Kebiasaan merokok pada pekerja pelabuhan diperoleh sebanyak $24,84 \%$ pekerja yang merokok menderita hipertensi lebih banyak dibanding pekerja yang tidak merokok sebanyak 19,61\% menderita hipertensi. Secara statistik tidak ada hubungan bermakna antara merokok dengan hipertensi (nilai $\mathrm{p}=0,27$ ) dengan POR 0,71 $(95 \%$ CI $=0,38-1,31)$. Sejatinya, nikotin pada rokok secara langsung akan meningkatkan tekanan darah bahkan pada pecandu sekalipun. Efek peningkatan tekanan darah memang sementara, sekitar 30 menit selama seseorang merokok. Namun, selama seseorang merokok tekanan darah tetap meningkat. Banyak penelitian yang menyatakan bahwa merokok merupakan faktor risiko hipertensi, berhenti merokok dapat mengurangi risiko hipertensi dan risiko penyakit kardiovaskular. ${ }^{10}$ Keterbatasan penelitian yang tidak menggali lebih jauh informasi tentang lama dan frekuensi merokok dalam kuesioner memberikan hasil yang berbeda dari teori yang ada.

Prevalesi hipertensi terjadi pada kalangan pekerja yang stres $(915,79 \%)$ daripada pekerja yang tidak stres $(23,51 \%)$. Pada penelitian ini, stres tidak berhubungan dengan kejadian hipertensi, hasil uji statistik didapatkan nilai $\mathrm{p}=0,06$ dengan $\mathrm{POR}=2,13(95 \% \mathrm{CI}=0,97-$ $4,67)$. Penelitian lain, ada hubungan signifikan antara stres kerja dengan hipertensi. Pekerja dengan stres kerja berat berisiko 1,55 kali mengalami hipertensi dari pekerja yang tidak mengalami stres. ${ }^{6}$ Stres akut dapat meningkatkan tekanan darah secara bermakna, tetapi peningkatan tekanan darah ini hanya berlangsung sementara. Stres yang berlangsung terus menerus dapat menimbulkan hipertensi, pada karyawan pria yang sehat, akibat tekanan pekerjaan adalah 3,1 kali lebih besar untuk menderita hipertensi. ${ }^{17}$

Peningkatan IMT diikuti dengan peningkatan prevalensi pekerja yang hipertensi adalah sekitar 15,53\% pekerja dengan IMT normal menderita hipertensi, pekerja yang gemuk sekitar $31,58 \%$ menderita hipertensi dan pekerja yang obesitas sekitar $38,81 \%$ menderita hipertensi. IMT menunjukkan hubungan bermakna dengan kejadian hipertensi, meskipun hasil uji statistik pada IMT gemuk didapatkan nilai $\mathrm{p}=0,26$, tetapi nilai $\mathrm{POR}=3,53$ dengan angka 95\% CI yang cukup lebar dan melewati angka $1(95 \% \mathrm{CI}=0,71-4,46)$. Demikian juga hasil uji statistik pada IMT obesitas didapatkan nilai $\mathrm{p}=0,11$ dan nilai POR 5,66 dengan angka 95\% CI yang juga cukup lebar dan melewati angka $1(95 \%$ CI $=0,67-47,54)$ Hubungan antara berat badan lebih dengan hipertensi dilaporkan oleh beberapa peneliti seperti Kaplan. ${ }^{18}$ Obesitas atau kelebihan berat badan akan mengaktifkan kerja jantung, dan dapat menyebabkan hipertrofi jantung dalam jangka lama, curah jantung, volume darah, dan tekanan darah akan cenderung naik.

Prevalensi pekerja yang hipertensi meningkat sesuai dengan lama masa kerja. Pada masa kerja $<6$ tahun $(17,2 \%), 6-12$ tahun $(17,44 \%)$ dan melonjak pada masa kerja $>12$ tahun yaitu 35,96\%. Namun, masa kerja tidak menunjukkan hubungan yang signifikan dengan kejadian hipertensi, hasil uji statistik pada masa kerja 6 -12 tahun didapatkan nilai $\mathrm{p}=0,07$ dengan $\mathrm{POR}=0,46$ $(95 \% \mathrm{CI}=0,19-1,06)$. Demikian juga pada masa kerja $>12$ tahun didapatkan nilai $\mathrm{p}=0,39$ dengan POR 0,66 $(95 \% \mathrm{CI}=0,25-1,74)$. Hasil yang sama yang tidak signifikan (nilai $\mathrm{p}=0,97$ ), dan pekerja yang bekerja lebih dari enam tahun berisiko lebih kecil untuk menderita hipertensi dari pekerja yang bekerja kurang dari enam tahun. 6

Area kerja tidak menunjukkan hubungan bermakna dengan hipertensi, hasil uji statistik didapatkan nilai $\mathrm{p}=$ 0,090 nilai POR 0,65 (95\% CI = 0,39-1,07). Diperoleh sekitar 25,90\% responden yang bekerja di area pelabuhan laut menderita hipertensi, sedangkan responden yang bekerja di area pelabuhan udara sekitar 18,46\% menderita hipertensi.

Pajanan kebisingan menunjukkan hubungan bermakna dengan hipertensi, hasil uji statistik didapatkan nilai $\mathrm{p}$ $=0,03$ nilai POR $=0,52(95 \% \mathrm{CI}=0,29-0,95)$. Sekitar $17,61 \%$ pekerja yang tidak terpajan kebisingan mengalami hipertensi, sedangkan pekerja yang terpajan kebisingan sebanyak 25,25\% mengalami hipertensi. Hasil analisis multivariat dengan menggunakan regresi logistik, faktor risiko yang dominan dengan kejadian hipertensi pada pekerja pelabuhan di wilayah kerja Kantor Kesehatan Pelabuhan Kelas II Tarakan adalah berusia lebih dari 42 tahun.

\section{Kesimpulan}

Prevalensi hipertensi pada penelitian ini adalah $21,88 \%$. Variabel usia, riwayat keluarga hipertensi, stres, indeks massa tubuh dan terpajan kebisingan mempunyai hubungan dengan kejadian hipertensi pada pekerja pelabuhan. Faktor yang dominan berpengaruh terhadap hipertensi pada pekerja pelabuhan adalah usia $>42$ tahun.

\section{Saran}

Kantor Kesehatan Pelabuhan Kelas II Tarakan bekerja sama dengan instansi terkait di wilayah kepelabuhanan untuk menggiatkan upaya-upaya advokasi, promosi dan penanggulangan hipertensi pada pekerja pelabuhan. Bagi 
pekerja pelabuhan, seiring dengan pertambahan usianya khususnya di atas 42 tahun agar menjaga berat badan ideal, membiasakan perilaku hidup sehat, olahraga teratur, menghindari stres, dan senantiasa melakukan kontrol tekanan darah.

\section{Daftar Pustaka}

1. Kementerian Kesehatan Republik Indonesia. Permenkes RI No. 2348; Organisasi dan tata kerja kantor kesehatan pelabuhan. Jakarta: Direktorat Pemberantasan Penyakit dan Penyehatan Lingkungan Kementerian Kesehatan Republik Indonesia; 2011.

2. Rahajeng E, Tuminah S. Prevalensi hipertensi dan determinannya di Indonesia. Majalah Kedokteran Indonesia. 2009 Des; 59 (12).

3. Kodim N. Analisis kontekstual hubungan lingkungan sosiodemografi dengan hipertensi yang tidak terkendali pada calon jamaah haji Indonesia [Disertasi]. Depok: Universitas Indonesia; 2004.

4. Kementerian Kesehatan Republik Indonesia. Pedoman teknis penemuan dan tatalaksana penyakit hipertensi. Jakarta: Direktorat Pemberantasan Penyakit dan Penyehatan Lingkungan Kementerian Kesehatan Republik Indonesia; 2006.

5. Astrid S. Penyakit akibat kerja dan penyakit yang berhubungan dengan pekerjaan, kesehatan dan keselamatan kerja. Jakarta: UI Press; 2002

6. Rundengan M. Hubungan pekerjaan dan stres kerja dengan kejadian hipertensi pada pekerja di Indonesia tahun 2005 [Tesis]. Depok: Univeersitas Indonesia; 2006.

7. Nirmawati. Identifikasi faktor risiko hipertensi pada anak buah kapal (ABK) yang terpajan bising di Direktorat Polisi Perairan Badan Pembinaan dan Keamanan Polri Tahun 2010 [Tesis]. Depok: Universitas Indonesia; 2006.
8. Wahyono TYM. Blood pressure survey in Indonesia [thesis]. Depok: Universitas Indonesia; 2003.

9. Parulian TH. Hubungan aktifitas fisik dengan risiko kejadian hipertensi tidak terkontrol pada lima wilayah di DKI Jakarta tahun 2006 [Tesis]. Depok: Universitas Indonesia; 2008.

10. Denio RA. Modifikasi gaya hidup dan tekanan darah, Majalah Kedokteran. 2007; 57 (3).

11. Soejono HC. Hipertensi sistolik terisolasi di Indonesia prevalensi dan faktor risiko [Tesis]. Depok: Universitas Indonesia; 2003.

12. Darmojo B. Mengamati perjalanan epidemiologi hipertensi di Indonesia. Medika. 2001; 7.

13. Kementerian Kesehatan Republik Indonesia. Laporan hasil riset kesehatan dasar (Riskesdas) Indonesia Tahun 2007. Jakarta: Balitbang Departemen Kesehatan Republik Indonesia; 2008.

14. Setiawan Z. Prevalensi dan determinan hipertensi di Pulau Jawa tahun 2004. KESMAS, Jurnal Kesehatan Masyarakat Nasional. 2006; 1 (2): 57-62.

15. Sheps SG. Is it true that sleep deprivation can cause high blood pressure [online]. Available from: www.mayoclinic.org/disease-conditions/highblood-pressure/expert.answer/sleep-deprivation/faq-20057959.

16. Fuentes RM, Motkola IL, Schemeikkas S, Tuomiehto J, Nissinen A. Familial aggregation of blood pressure. Journal of Human Hypertension. 2000; 14: 441-5.

17. Markum H. Penatalaksanaan hipertensi pada pekerja. Seminar standarisasi dan sertifikasi keselamatan kerja, manajemen ergonomi dan promosi kesehatan pekerja. 1996 Des 5-6; Jakarta, Indonesia. Depok: Fakultas Kesehatan Masyarakat Universitas Indonesia; 1996.

18. Kaplan NM, Liebermann E, Neal W, editors. Kaplan's Clinical Hypertension. $8^{\text {th }}$ ed. Philadelphi: Lippincott Williams \& Wilkins; 2002. 